\title{
Research of Internet Financing Strategy of Small and Micro Enterprises Lijuan Liư ${ }^{1, a}$ \\ ${ }^{1}$ Shaanxi Institute of International Trade \& Commerce, Xi'an, Shaanxi, 712046 \\ a email
}

Keywords: Small and Micro Enterprises, Financing Strategy, Internet Financing

\begin{abstract}
With the rapid development of information technology and finance industries, Internet and financial double-acting become increasingly apparent. In both the role of the Internet financing is developing rapidly. Compared with traditional financing, Internet financing data is to the Internet-based, network as a platform to achieve the extension and expansion of traditional financial services. Internet finance in small and micro enterprises solve the financing problem on a great advantage. As for funding the demand side of small and micro enterprises, through the Internet financing costs, improve processes on, greatly reducing transaction costs and accelerate lending efficiency, can greatly enhance the rate of small businesses obtain financing. Small and micro business financing has always been a problem worldwide. In China, traditional commercial banks and other financial institutions, higher loan threshold so that many small and micro enterprises prohibitive, coupled with higher interest private loans, the financial pressure to survive in the cracks of small and micro enterprises are facing growing. With the maturity of Internet technology, especially mobile payment landscape, cloud computing and search engines have sprung up everywhere, the financial industry has undergone tremendous changes. Internet financing, once launched, because of its open, democratic, tolerant, convenient, efficient and targeted, and many other advantages, the industry is widely expected that it will effectively resolve A small, micro-enterprise financing dilemma of new ways for small and micro business is a huge opportunity for development.
\end{abstract}

\section{Introduction}

Most small and micro enterprise financing sources are primarily non-financial institutions, funds, that is self-financing, private funding. Since the stock market financing conditions are higher, making the feasibility of financing equity financing is not high, resulting in the majority of small businesses unable to obtain funds from the capital markets. Financing amount of the commercial banks and other financial institutions are to provide a relatively small. Therefore, small and micro enterprises mainly rely on friends and family and other social idle funds and private credit funds. According to data in 2011, Peking University and Zhejiang Alibaba 2313 small micro-enterprise joint survey shows that only 15\% of businesses to obtain loans from banks, and another 22 percent do not outwardly financing. In the rest of the corporate finance, the proportion of relatives and friends from $29 \%$ to $21 \%$ of private lending, small loan companies is $7 \%$, the steering usury $1 \%$; According to data in 2014 "two sessions" of the proposal showed that 90 per cent of private enterprises facing financing difficulties.

\section{Internet Financing Advantage for Small and Micro-Enterprise Financing Problems}

Modern history shows that the company's development, enterprises from scratch, from small to large, and its continued development relies mainly on funding from the continuous self-accumulation of capital, the enterprise's own funds is an important guarantee for its continued development and growth. Small businesses because of their small scale, and has no competitive advantage, the majority of enterprises in the start-up stage, a serious shortage of own funds, which not only restricts the normal development of the enterprise, is not conducive to improve its financing conditions, so that small and micro enterprises are facing serious financing difficulties.

This is the small businesses cannot get credit for a very important internal reasons. Small 
businesses because of their lack of management, business performance is unstable, small, vulnerable to market fluctuations. In addition, their credit rating is low, and the financial management is not standardized, they are not conducive to their access to capital needed for business development from commercial banks.

The results of the State Council Development Research Center data show that, at this stage can melt from the capital markets to finance small and micro enterprises are still small, and higher financing costs, financing costs on average between 10\% -15\%. Most small and micro enterprises are faced with the high cost of funds, funding strand breaks a greater risk of social reality. Higher commercial bank loan threshold so that the majority of small businesses have been shut out, which makes small and micro enterprise financing costs continue to increase.

Along with China's openness to deepen the financial sector, commercial bank loan guarantee system required for continuous improvement, a relatively high collateral requirements, most of the security agencies do not want to run unstable performance, smaller size, fixed assets is not high small and micro enterprises to be secured, not to mention small and micro enterprises have no guarantee of higher quality assets, which limits the use of small and micro enterprises existing security system for financing economic activities.

Although in recent years, China has conducted a series of financial sector reforms, it has made many achievements, but our financial resources remain highly concentrated. According to public information Financing Regulatory Commission show that as at the end of 2013, China's financing institutions a total of 3747 legal entities and financial assets are mainly concentrated in large state-owned commercial joint-stock banks. Coupled with the loan program of commercial bank credit institution is relatively complex and relatively strict examination and approval, the formation of a higher threshold Financing System, which makes it smaller and unstable operating small businesses would rather give up the loans from commercial banks in favor of loans to private institutions. Compared with large enterprises, small and micro enterprises do not have equal access to funds from commercial banks, which requires the government continues to improve the financial system, optimize the rational allocation of financial resources.

\section{The Advices to Complete Small Micro-Enterprise Financing Mode}

With the development of market economy increasingly deepening, the modern market for enterprise-level requirements continue to increase, and therefore the needs of modern enterprises to continuously strengthen self-construction. Small and micro businesses can change the mode of production from start to strengthen itself. First, the standardization of business. Small and micro enterprises should be changed as soon as possible the traditional "family - style" management approach, starting from their own health professional to introduce professional managers mechanism, establish standardized modern enterprise financial, personnel and other management mechanisms, improve their information with transparency and comprehensiveness, reduce and the degree of information asymmetry between financial institutions, reducing the risk of both lenders and borrowers. Second, to improve the information capabilities. Information refers to the ability to understand, access, and use of information can provide the ability to use information technology. Understand the information that is information for analysis, evaluation and decision-making. Strengthen their own information to explore, in-depth use of information resources, strengthening information technology and other aspects, information or consult professionals advice.

Update information and knowledge in today's society more and more quickly, not only individuals should continue to strengthen their own learning, enterprises should begin to enhance learning from the corporate culture. At present, China's small and micro enterprises to master the knowledge and financial resources are insufficient, I believe that small businesses should take the initiative to learn the financial knowledge to understand the basics of financing; enhance credit awareness, focus on integrity management; proactive understanding of Internet financing characteristics of current development, business process Internet financing and various financing between pursuant to select suitable for the enterprise financing. For example, when small businesses understand their floating capital demand, understand P2P, similarities and differences between the 
electricity supplier and crowdfunding large financial data $\mathrm{H}$ seed financing model, but also consider the mother ant microfinance and Jingdong supply chain in terms of costs, services, etc. the difference between small micro-finance and other different financial model between naturally very easy to choose their own mode of financing the Internet, post financing process can be done will be in a few, timely adjustment of strategies.

Small and micro enterprises in the business process, pay attention to the accumulation of a good credit record. With the extensive application of information technology applications, especially in big data, cloud computing technology, information can be obtained anywhere. Modern Internet-based information age, whether individuals or organizations, in the process of production and business activities, and will have left many of the data in all fields, through the analysis of these data can get a lot of important information. At present, many small and micro businesses often pay no attention to these issues, think he is wise, and finally picking up a pound-foolish. The $1 \wedge$, small and micro enterprises in the production and management process to uphold the integrity of management, when in contact with the various aspects of society needs to pay attention to the accumulation of credit, credit guarantee this basic financing.

Internet companies should make the financial sector to highlight their own advantages, mainly its own technology, data, channel edge. Internet financial enterprises and traditional financial institutions compared to the presence of many natural disadvantages, such as lack of financial experience in product design, regulatory policy uncertainty, risk management mechanisms without PubMed and other newer, but at the same time, financial companies mostly rely on Internet technology fortune through years of accumulated data, the use of cloud computing, big data and other technologies for financial services. Internet companies cannot also lose their nuclear superiority, should the larger energy into propulsion technology innovation and progress, using the platform of the strategy, the establishment of binding data, channels, technology of a professional platform. Each combination of different sources of information is to make full use of the value of information. Implementation information and data together to share, it is easier to implement innovative financial products and services.

Accumulation of data and information of the Internet long-term financial firms, at the right time with the latest information technologies for data processing, and continuously explore and analyze the financing needs of small and micro enterprises, in large measure to solve the financing credit information asymmetry. Improve the efficiency of small micro-enterprise financing, and to establish a unique enterprise credit evaluation system in order to manage risk. However, these credit evaluation systems are still in the nascent stage, but also because of the nature of information technology, there is a wide range of issues such as security, reliability, comprehensiveness and the like. Thus, the concept of the Internet gold companies must continue to strengthen risk management, for example through innovations in information technology, to solve the credit network in a specific operational difficulties and other issues; side through inquiries small and micro enterprises taxation, utilities, small and micro business owners personal social network aspects of evaluation, bank credit records, etc. to enrich their own credit rating system. Financial risk management is the lifeblood of the Internet financial enterprises need to strengthen risk management.

Mom ant microfinance and financial Jingdong other companies are the advantages of Internet companies will play out, stand on the perspective of industrial chain, the business ecosystem of view, are a combination of the characteristics of small and micro businesses and their own platform designed a number of products and services, and for different small and micro enterprises and adopt a differentiated and personalized strategies. These are also factors in the Internet core financial enterprises the rapid development lies, therefore, in order to long-term healthy development of the Internet financial enterprises should continue to promote financial innovation in product design and service process optimization. Can continue through cloud computing and big data technologies such as the financing needs of small and micro enterprises to further mining, refining, provide more flexible solutions from operational processes, customer eligibility, repayment period, repayment method, interest rate and other loan terms, provide a more personalized and targeted financial services, this increase customer loyalty and satisfaction, and achieve long-term development. 


\section{Conclusion}

Internet financing financing model has a Pratt \& Whitney, convenience, relevance, etc., can solve the problem of financing small and micro enterprises, the advantages of having a collaboration between Internet financing and small micro-enterprise financing. The traditional financing channels for small and micro enterprises into direct financing and indirect financing, from the point of view of supply and demand financing needs of small and micro enterprises and Internet financial supply, and the corresponding demand and supply are matched to small and micro corporate financing model summarized as peer financing model based on micro-credit financing models big data, the public funding financing mode and Internet portals financial institutions financing model four main modes. With respect to the existing small and micro enterprise financing mode, the network unprofor financing model to better address the small micro-enterprise financing process mortgage problem, the network credit pool model can improve the access threshold internet financing platform, to better promote the healthy development of the Internet in financial markets, while equity financing model is better able to enhance the small micro-enterprise capital strength and reduce the risk of bankruptcy of small and micro enterprises, and ultimately promote the sustained, healthy and rapid development of small and micro enterprises, so that small and micro companies really bigger and stronger.

\section{Acknowledgements}

Shaanxi Provincial Department of Education issues: Financial Innovation Internet and Shaanxi Province SME financing model, 2015 Shaanxi Department of Education issues, project number: 15JK2010.

\section{References}

[1] Halstead Alison. Attracting Micro-Enterprises to Learning Community Initiatives or Growth Incentives [J]. Community, Work \& Family, 2004 (9): P11-13.

[2] Visser. M. Anne. The Continuum of Capital for Small and Micro Enterprise [J]. Journal of Developmental Entrepreneurship, 2005 (17): 19-22.

[3] Valentina Hartarska. What Affects New and Established Firms Expansion, Evidence From

. Small Firms in Russia Final Version Accepted, 2006 (2): Pp195-206.

[4] Steve Beck, Tim Ogden. Beware of Bad Microcredit [J]. Harvard Business Review, 2007 (9): 20-21.

[5] Thorsten Beck. Small and Medium Enterprises Across The Globe [J]. Small Business Economics, 2007 (4): 416-433.

[6] Beger S. and F. Cleimdr. Emergence of Financial Intemediaries on Electronic Markets: The Case of Online P2P Lending [D]. Working Paper, University of Frankfun, 2008. 